\title{
RICE (KHARIF) PRODUCTION ESTIMATION USING SAR DATA OF DIFFERENT SATELLITES AND YIELD MODELS: A COMPARATIVE ANALYSIS OF THE ESTIMATES GENERATED UNDER FASAL PROJECT
}

\author{
Varunika Jain*, Shalini Saxena, Sunil Dubey, Karan Choudhary, Seema Sehgal, Neetu and S. S. Ray \\ Mahalanobis National Crop Forecast Centre DAC\&FW, New Delhi 110 012, India \\ (varunika15jain, seemasehga193)@gmail.com; (shalini.85, sunil.dubey86, karan.c)@gov.in; (neetu.ncfc, shibendu.ncfc)@nic.in
}

\section{Commission III, WG III/10}

\begin{abstract}
KEY WORDS: FASAL, Rice, Radarsat-2, RISAT-1, Sentinel-1, Synthetic Aperture Radar data, HH, VV, HDRC, RMSE, R², Paddy
\end{abstract}

\begin{abstract}
:
Rice is the most important food crop of India. Majority of Rice is sown in kharif season in the country. This is monsoon season for the country where cloud cover poses a major problem for optical remote sensing. Therefore, for these states rice acreage estimation is being done using Synthetic Aperture Radar (SAR) data operationally in India since 1998. A case study is presented in this paper for analysis of past 6 years' (2012-13 to 2017-18) estimations. Multi temporal Radarsat-2 (HH), RISAT-1 ScanSAR (HH) and Sentinel-1 (VV) data was used in years 2012, 2013-2016, and 2017, respectively for paddy identification. Hierarchal Decision Rule based classification (HDRC) approach was used to identify rice areas under sample segments. Extensive ground truth collected by state remote sensing departments and agriculture departments was utilized in setting the limits of HDRC models and accuracy assessment. Yield was estimated using weather based and remote sensing-based models. Area, production and yield estimates were made and compared with those given by DES. RMSE and $\mathrm{R}^{2}$ were used as statistical measures to assess the accuracy of results. The RMSE \% ranged from 2.3 to $4.3 ; 0.84$ to $1.35 ; 0.24$ to 0.27 for area, production and yield respectively. The coefficient of determination $\left(\mathrm{R}^{2}\right)$ ranged from 0.62 to $0.92 ; 0.75$ to $0.91 ; 0.5$ to 0.83 for area, production and yield respectively. The study showed that use of multi temporal SAR data (both $\mathrm{HH}$ and $\mathrm{VV}$ ) is quite useful for paddy acreage estimation, especially during monsoon.
\end{abstract}

\section{INTRODUCTION}

Rice is the most important food crop of India and it is the second largest rice producing country (after China) of the world. Rice plays an important role in India's diet and source of livelihood for millions of households. It is having high economic importance as well as central to food security in the country. Rice is the staple food crop for more than $70 \%$ of Indian people and ninety per cent of the rice produced is consumed within the country (Varma 2017). Rice is grown mainly in two seasons (kharif and rabi) in the country and major share is cultivated during kharif season as it demands temperature around $25^{\circ} \mathrm{C}$ and above, and rainfall more than 100 $\mathrm{cm}$. Irrigation is provided in the areas receiving comparatively less rainfall in the kharif season. The sowing of kharif rice starts in June-July and harvested in October- November. Rice (Kharif) accounts for $37 \%$ of the total kharif sown area and $70 \%$ of kharif food grain production in the country (MNCFC/FASAL/ 2017/01).

Timely and reliable estimate of crop area and production is important to support food crop management and food security programmes. Satellite based remote sensing data analysis has been playing vital role in pre harvest crop acreage estimation. Crop acreage estimation presents several challenges and complexities, which may not be readily apparent (Craig and Atkinson 2013). Small field sizes, diversified cropping pattern, different crop sowing time, availability of satellite data are some of the major challenges in estimation of crop area using remote sensing data. These problems can be overcome by estimation at multiple stages: before sowing (specifically, the date of intended sowing, which depends upon the profits obtained in the previous year from the crop and weather forecasts); during early sowing; at mid-season and before harvest (Vogel and Bange 1999). Kharif Rice is the monsoon season crop which is dominated by clouds and haze most of the time. This makes its estimation through optical remote sensing a challenging task. Such disadvantages are alleviated using microwave SAR (Synthetic Aperture Radar), which is an active sensor and has all weather capabilities (Panigrahy et al., 2000).

SAR becomes more convenient as it uses its own source of illumination and is able to operate both day and night with capability to penetrate through clouds. Sensing in the microwave portion of the electromagnetic spectrum makes SAR data well-suited for discriminating among vegetation types because the scattering at these longer wavelengths is driven by crop-specific larger-scale structures (size, shape and orientation of leaves, stems and fruit) as well as by the volume of water in the vegetation canopy (at the molecule level) (Inoue et al., 2002).

Multi-date Risat-1 C-band with HH polarization SAR data has been continuously used for kharif and rabi rice acreage estimation in India under FASAL program since 2013 (Ray \& Neetu, 2017, Ray et al., 2016). In several studies, the SAR Cband with shallow incidence angle $\left(31-46^{\circ}\right)$ have been found suitable for mapping of rice crops (V. Jain et al 2014, Lam-Dao et al, 2005). Sensitivity of SAR data to flooded condition and crop geometry (Henderson and Lewis 1998) make it possible to map rice fields. The multi-date SAR data analysis approach takes advantage of the strong temporal variation of radar backscattering from paddy fields during transplanting to growing stage of the crop (Choudhury et al. 2011).

A case study is presented in this paper for analysis of past 6 years' (2012-13 to 2017-18) estimations. Multi temporal

\footnotetext{
* Corresponding author
} 
Radarsat-2 data was used in 2012, RISAT-1 ScanSAR (HH) data was used in years 2013 to 2016, whereas in 2017 Sentinel1 (VV) data was used for paddy identification. FASAL (Forecasting Agricultural output using Space, Agrometeorology and Land based observations) is the major operational programme of Ministry of Agriculture and Farmers Welfare, Govt of India under which MNCFC (Mahalanobis National Crop Forecast Centre) has been regularly generating multiple pre-harvest crop acreage and production forecasts at District/State/National level for major crops of the country since 2012. Ever since the Sentinell was launched in April 2014, a few attempts have been made to map rice crop using Sentinel 1A VV data (C.F Chen et al 2016) with considerable classification accuracy. In 2017, Sentinel 1A data was used for operational kharif rice acreage estimation of the country for the first time. The maximum paper length is restricted to 8 pages. Invited papers can be increased to 12 pages. The paper should have the following structure:

\section{STUDY AREA}

India is one of the largest producers of rice in the world, accounting for $20 \%$ of all world rice production. Rice is grown in most part of the country reflecting its adaptability to grow under diverse climatic and soil conditions. It is grown in coastal areas, deltaic regions, northern plains and northeast India. Study area for which kharif rice area estimation is carried out include 14 major rice growing states of India. The states are Andhra Pradesh, Assam, Bihar, Chhattisgarh, Karnataka, Haryana, Jharkhand, Madhya Pradesh, Odisha, Punjab, Telangana, Tamil Nadu, Uttar Pradesh and West Bengal (Figure 1).

The eastern and north-eastern region comprising of Assam, Bihar, Chhattisgarh, Jharkhand, Madhya Pradesh, Orissa, Eastern Uttar Pradesh and West Bengal receive high rainfall in monsoon season and rice is grown for the most part under rain fed conditions. The northern region consists of Haryana, Punjab, Western Uttar Pradesh, and southern (Andhra Pradesh, Karnataka, Telangana and Tamil Nadu), receive comparatively less rainfall and rice is grown mainly under irrigated conditions. These 14 states cover $89.5 \%$ of total Kharif rice area and $91.14 \%$ of the total Kharif Rice production of the country (DES, 2010-11 to 2015-16). The states with higher contribution to national rice production include Uttar Pradesh (14\%), Punjab $(12 \%)$ and West Bengal (12\%).

\section{MATERIALS AND METHODS}

\subsection{Satellite Data}

Radarsat-2 ScanSAR Narrow B data was used for the year 2012. RISAT-1 ScanSAR MRS (medium resolution) data was used for the years 2013, 2014, 2015 and 2016. Sentinel-1A GRD data was used for 2017-18. All the 3 satellites have payloads of Synthetic Aperture Radar in $\mathrm{C}$ band that provides continuous imagery (day, night and all weather). Radarsat- 2 is a Canadian satellite and its data distribution is managed by MDA. RISAT-1 was Indian satellite launched by Indian Space Research Organization.

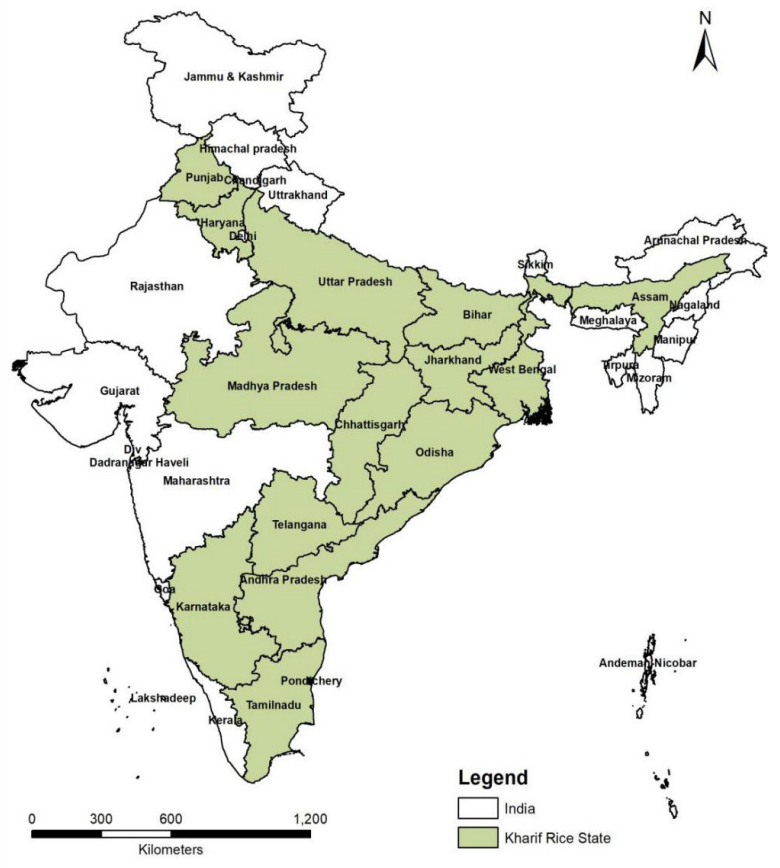

Figure 1. Study area map, showing the states for which kharif rice acreage estimation is carried out.

Sentinel-1 is a space mission funded by the European Union and carried out by the European Space Agency within the Copernicus Programme, consisting of a constellation of two satellites.

This data is available free of cost. 2017 was the first time, when Sentinel 1 data was used for national level Kharif Rice area estimation. The specifications of Radarsat-2, RISAT-1 and Sentinel $1 \mathrm{C}$ band SAR data are given in Table 1

\begin{tabular}{|c|c|c|c|}
\hline Band & Radarsat-2 & RISAT-1 & Sentinel-1 \\
\hline Polarization & HH, HV & HH, HV & VV, VH \\
\hline Mode & $\begin{array}{c}\text { ScanSAR } \\
\text { Narrow B }\end{array}$ & $\begin{array}{c}\text { Medium } \\
\text { Resolution }\end{array}$ & $\begin{array}{c}\text { Interferometri } \\
\text { c Wide }\end{array}$ \\
\hline $\begin{array}{c}\text { Product Type } \\
\text { Range }\end{array}$ & $\begin{array}{c}\text { Rround } \\
\text { Range }\end{array}$ & $\begin{array}{c}\text { Ground } \\
\text { ed }\end{array}$ \\
\hline $\begin{array}{c}\text { Incidence Angl } \\
\text { e (Central) }\end{array}$ & $38.7^{\circ}$ & $36.0^{\circ}$ & $38.3^{\circ}$ \\
\hline $\begin{array}{c}\text { Ground Range } \\
\text { Resolution (ran } \\
\text { ge * azimuth) }\end{array}$ & $298 \mathrm{~km}$ & $115 \mathrm{~km}$ & $251.8 \mathrm{~km}$ \\
\hline Repeativity & 24 days & 25 days & 12 days \\
\hline
\end{tabular}

Table 1. Specifications of Satellite based SAR data used for rice area estimation 
For Punjab and Haryana, data from May end to early August was used, while for other states data of June/July to September was used. Example of a multi-date Sentinel data showing rice classes is given in figure 2 .

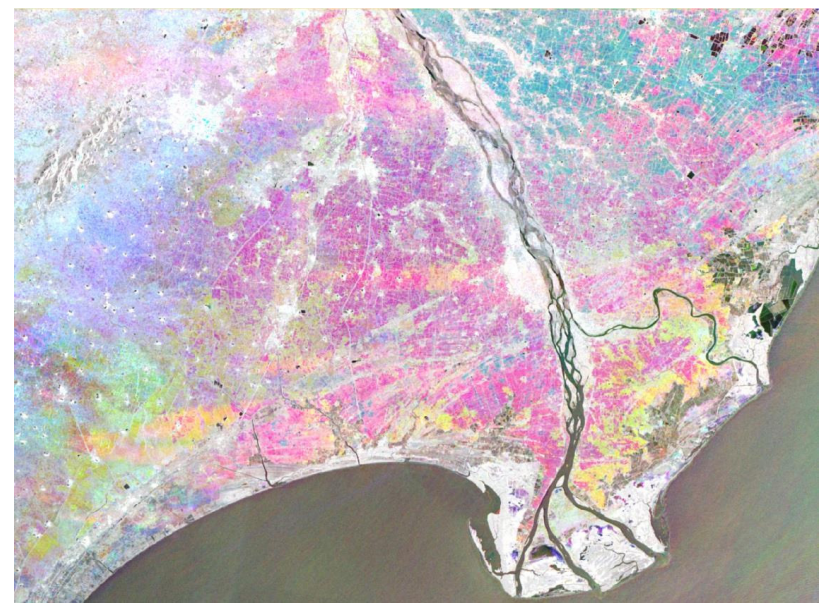

Figure 2. Paddy area in Krishna, Guntur Districts of Andhra Pradesh: Colour composites of 28 July (Red),21 August

(Green), 14 September (Blue)

\begin{tabular}{|c|c|c|}
\hline Year & $\begin{array}{c}\text { Satellite } \\
\text { Data }\end{array}$ & $\begin{array}{c}\text { Summary of } \\
\text { Approach }\end{array}$ \\
\hline 2012 & $\begin{array}{l}\text { Radarsat-2 } \\
\text { SacnSAR }\end{array}$ & $\begin{array}{l}\text { State level \& National Level, Multi } \\
\text { temporal, Sample segments, HDRC* } \\
\text { based analysis }\end{array}$ \\
\hline 2013 & $\begin{array}{l}\text { RISAT-1 } \\
\text { ScanSAR }\end{array}$ & $\begin{array}{l}\text { State level \& National Level, Multi } \\
\text { temporal, Sample segments, HDRC } \\
\text { based analysis }\end{array}$ \\
\hline 2014 & $\begin{array}{l}\text { RISA } \\
\text { Scans }\end{array}$ & $\begin{array}{l}\text { District level, State level \& National L } \\
\text { evel, Multi temporal, Sample } \\
\text { segments, HDRC based analysis }\end{array}$ \\
\hline 2015 & $\begin{array}{l}\text { RISA } \\
\text { Scans }\end{array}$ & $\begin{array}{l}\text { District level, State level \& National L } \\
\text { evel, Multi temporal, Sample } \\
\text { segments, HDRC based analysis }\end{array}$ \\
\hline 2016 & $\begin{array}{l}\text { RISAT-1 } \\
\text { ScanSAR }\end{array}$ & $\begin{array}{l}\text { District level, State level \& National L } \\
\text { evel, Multi temporal, Sample } \\
\text { segments, HDRC based analysis }\end{array}$ \\
\hline 2017 & $\begin{array}{l}\text { Sentinel-1 } \\
\text { GRD }\end{array}$ & $\begin{array}{l}\text { District level, State level \& National L } \\
\text { evel, Multi temporal, Sample } \\
\text { segments, HDRC based analysis }\end{array}$ \\
\hline
\end{tabular}

*HDRC-Hierarchical Decision Rule based Classifier

Table 2. Year wise Approach followed for paddy area estimation.

\subsection{Ground Truth Data}

Ground truth data collection is essential for the analysis of remote sensing data for differentiating various land uses and land covers. The major reasons to conduct ground truth activities include (a) To obtain relevant data and information helpful as inputs and reference in the analysis of a remotely sensed data and (b) To verify that what has been identified and classified using remote sensing data is actually correct (accuracy assessment). The MNCFC is collaborated with State Agriculture Departments and State Remote Sensing Centres for collecting ground information. The ground truth data is collected by the state government officials using a smartphonebased Android application, called Bhuvan FASAL, developed by NRSC (ISRO). The application is used to collect attribute information related to ground truth feature observed along with filed photograph and sketch which can be directly uploaded to Bhuvan Geoportal server in real time manner. The basic information collected during ground truth collection are type of crop, GPS location (Latitude \& Longitude), field size, crop growth stage, crop health condition, ground cover, sowing/transplantation date of crop, expected date of harvest and soil condition etc in tabular form. The field photographs (overview and close view), an asterisk mark (position of GPS location) and field ID are also collected which gives an idea about the field when associated with remote sensing data. The ground truth data for rice crop was collected during JulySeptember each year.

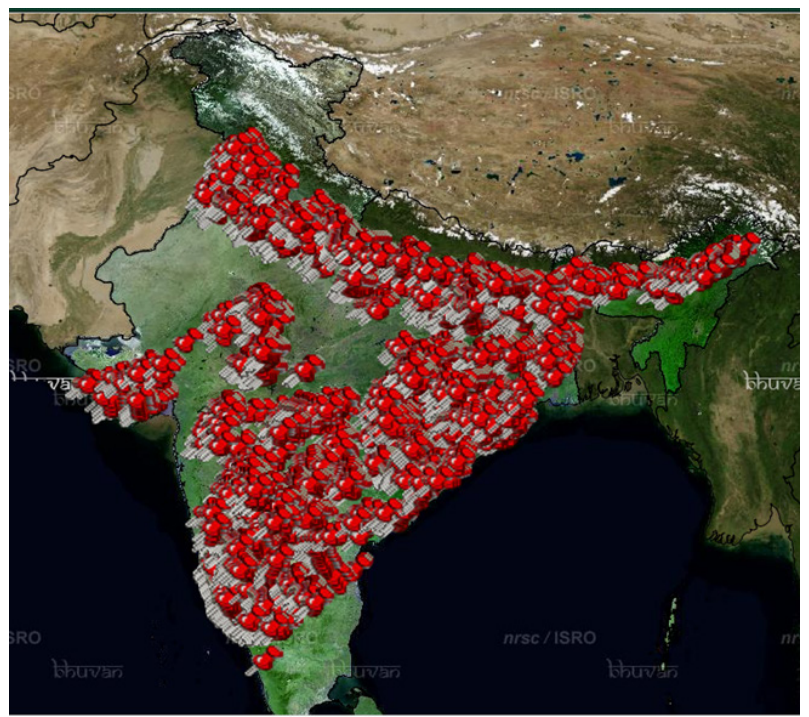

Figure 3. Overview of Ground truth points for Haryana state, collected during August/September, 2017

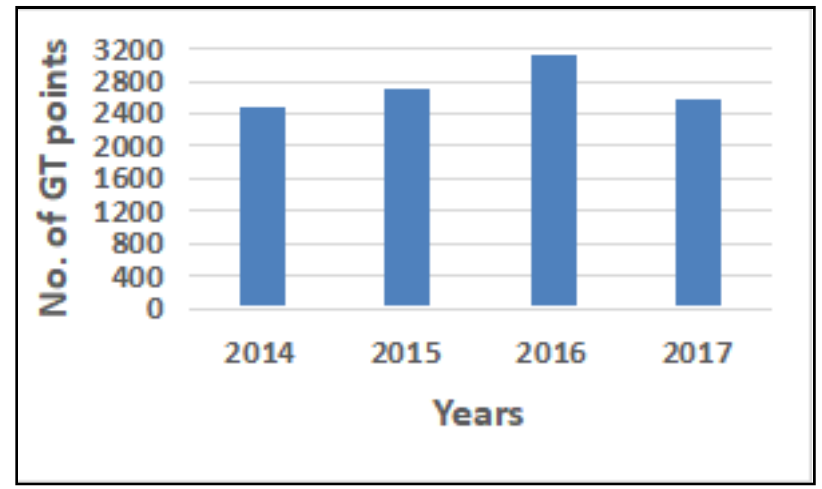

Figure 4. Ground truth data collected for different years 


\subsection{Sampling Approach}

The area estimation is carried out using multi-date satellite data following a stratified random sampling approach. Generally, 4 strata are formed based on the extent of rice pixels in each segment $(5 \times 5 \mathrm{~km}$ size $)$. For example, the segments under $\mathrm{A}$ stratum will have $>75 \%$ of rice area, B: $50-75 \%$, C: $25-50 \%$, D: $<25 \%$ (Figure 5). Essentially $15 \%$ of the total segments (stratified as given above) are taken as sample segments. The rice crop classification is carried out within these stratified random sample segments and then through statistical aggregation the area estimation is carried out at district/state level. This approach is followed to minimise the errors due to omission and commission in classification.

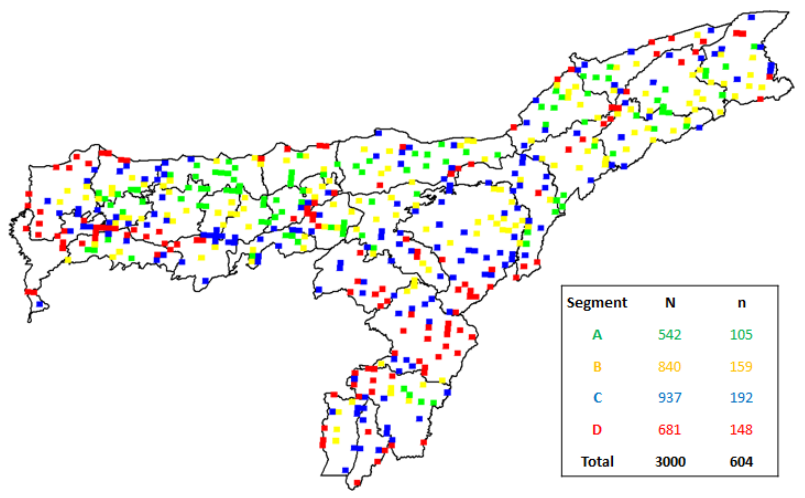

Figure 5. An example of sample segments selected for rice classification in Assam state

Ground truth sites, which are overlaid on the image, are used to identify the rice and other crop pixels. Classification rules are formed based on the pixels identified using GT data. A logical classification is followed, based on the temporal behaviour of Rice crop as shown in microwave data (backscatter values). The steps of Sentinel data analysis for rice acreage estimation are given in Figure 6.

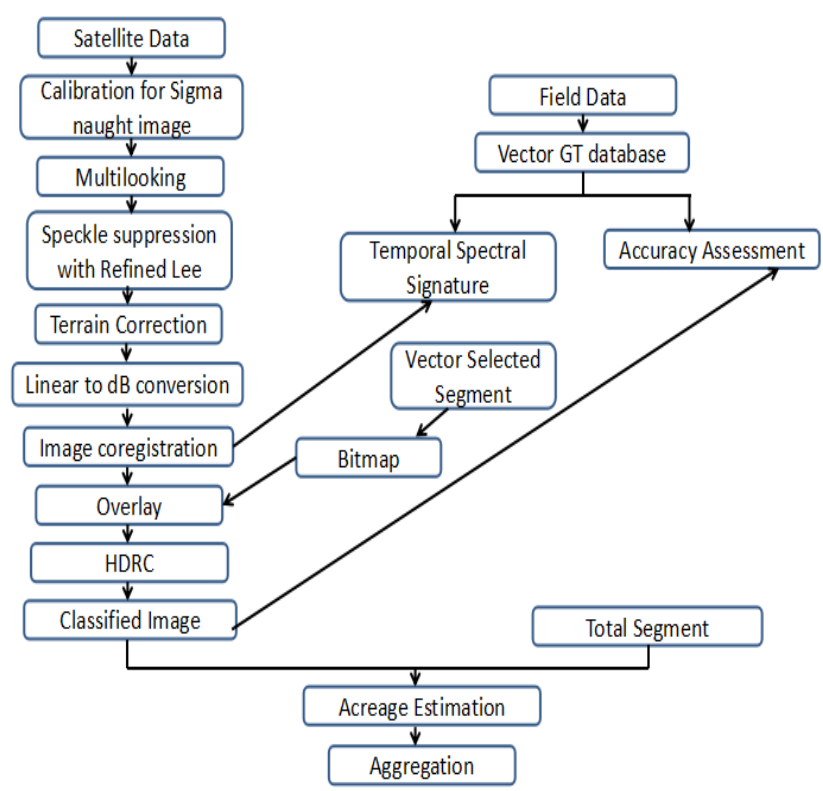

\subsection{Data Pre Processing}

Radarsat-2 data was ordered from MDA for the years 2012 and 2013. RISAT ScanSAR data was ordered from NRSC for the years 2014,2015 and 2016. Pre-processing of both Radarsat-2 and RISAT-1 data was done in Fasalsoft; an indigenously developed software by Space Applications Centre (ISRO). Sentinel-1 data was downloaded from ESA Copernicus website for the year 2017. Area of interest was selected and sensor input parameters viz; date of sensing, sensor platform - 1A, product type - GRD product, polarization - VV VH, mode - IW, were provided for scenes to be downloaded for further analysis. Once the requisite scenes were downloaded pre-processing was carried out in SNAP software (an open source software of ESA) to prepare dataset. Following steps were followed: Calibration, multilooking, Speckle Filtering, Terrain Correction, linear to dB conversion.

Calibration is done to radiometrically correct a SAR image so that the pixel values truly represent the radar backscatter of the reflecting surface. Essentially sigma naught product is generated. Multilook is performed to produce a product with nominal image pixel size. As a result of multilooking the radiometric resolution improves but spatial resolution degrades. In this study $2 * 2$ multilooking was used. Image would have less noise after multilooking. Speckle is caused by random constructive and destructive interference resulting in salt and pepper effect throughout the image. Speckle suppression is applied to reduce the noise at the same time compromising the spatial resolution. For our purpose we used Refined Lee filter as it is an adaptive filter. Terrain correction was carried out to geocode the image by correcting SAR geometric distortions using a DEM. A map projected product was output. Finally, to reduce the value range of the image data linear to $\mathrm{dB}$ conversion was done. The final image was exported as .geotiff image.

The above obtained image was scaled to 255 value range to reduce the image size as well as making it more user friendly for classification. Multitemporal dataset was created by using layer stack function in ERDAS. This dataset was used for paddy classification.

\subsection{Classification}

Classification was a two-step process comprising of optimum date selection and paddy classification. Unsupervised classification was carried out on the above obtained dataset. The means of each date for all classes were calculated. Temporal graphs were generated for all the classes and classes showing typical paddy signatures were selected (Figure 7, 8, 9). Major transplantation dates were noted and corresponding scenes were selected for classification of paddy area. Transplantation date is essentially a scene where there is a dip in backscatter values similar to that of water (about -17 to -18 $\mathrm{dB})$, with a subsequent increase in backscatter values corresponding to crop growth and increase in biomass. Essentially 24 days' gap was taken between selected layers to be used in classification.

Hierarchal decision rule-based classification was carried out using the selected layers. Typical paddy signatures being:

$-16<\mathrm{D} 1<-12,-13<\mathrm{D} 2<-10,-10<\mathrm{D} 3<-7$

Figure 6: Flow diagram for SAR data analysis 
where all values are in deci Bels $(\mathrm{dB})$ and $\mathrm{D} 1, \mathrm{D} 2, \mathrm{D} 3$ correspond to first date layer, second date layer, third date layer respectively.

For accuracy purposes classification was carried out under selected segments only. The district or state paddy area was calculated by extrapolation of the values received from sample segments.

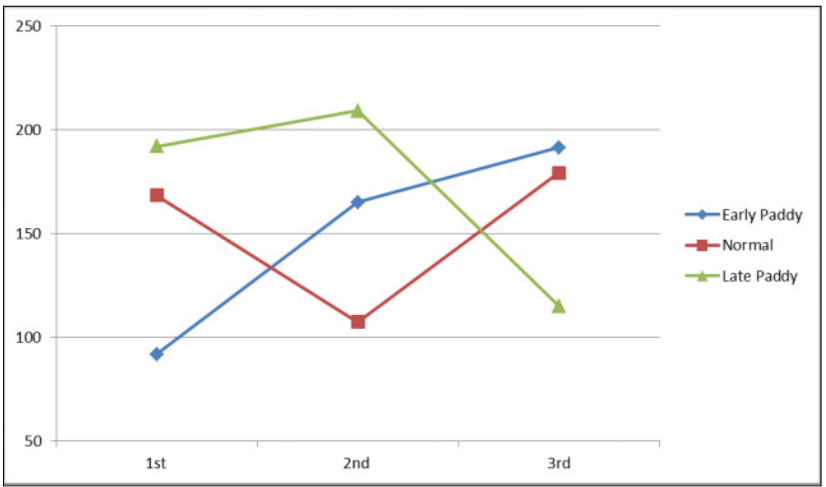

Figure 7: Paddy signatures as obtained from multi-temporal RISAT-1 dataset (scaled values to 255) 2016, Assam.

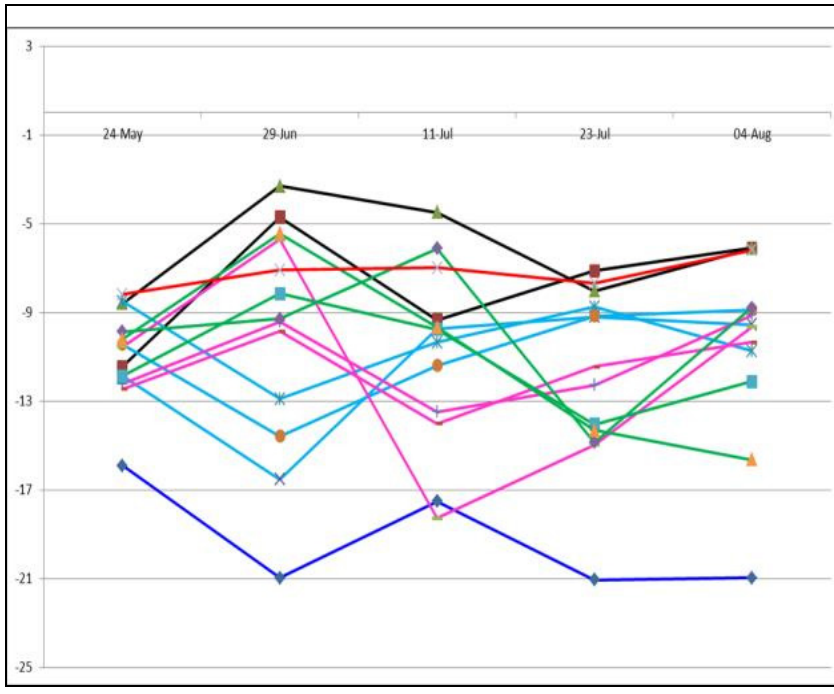

Figure 8: Signatures as obtained from Sentinel-1 multi-temporal dataset 2017, Andhra Pradesh ( Paddy early: sky blue, paddy normal: pink, paddy late: green, water body: dark blue, forest scrub: Red, cotton: black )

\subsection{Area Estimation}

The district rice area was calculated by statistical aggregation of the values received from sample segments.

$$
A=\sum_{i=1}^{i=4} \bar{X}_{\imath} \cdot N_{i}
$$

where $\quad A=$ Area of crop within a district

$\mathrm{i}=$ Number of stratum (here 4$)$

$\bar{X}_{2}=$ Average of rice area in sample segments of the ith stratum

$\mathrm{Ni}=$ Number of segments in the district for i-th stratum
The district wise rice areas were added to get the state level rice area. Wherever all districts were not analysed, the study districts' rice area total was multiplied with an extrapolation factor (based on last 3 years' DES data) to get the state level area. The states of Assam, Bihar, Jharkhand, Odisha and West Bengal have autumn and winter rice, which are together called total kharif. Since this analysis is only for the kharif rice, in these states, an extrapolation factor (based on last 3 years' DES data) was used to get total kharif rice.

\subsection{Monitoring of rice transplantation growth using multi- temporal data}

It is important to monitor the temporal variation in paddy transplantation phase and the peak transplantation period in particular area or region. Availability of Sentinel 1A data (in 2017) with repeat cycle of 12 days for each area made it possible to monitor the temporal pattern of rice planting in the study area. During the rice transplantation, fields are inundated with water and the sensitivity of SAR data to water aids to form the rules to extract the rice pixels at or near transplantation stage. Temporal pattern of rice transplantation was monitored at 12- or 24-days interval in each study state based on the availability of data. To verify the transplanting period extracted using SAR data, ground truth information is utilized and the results obtained through remote sensing data were compared with the field data.

\subsection{Yield estimation}

District level Rice crop yield was estimated using three different procedures - i) Agro- meteorological regression models, ii) Crop Simulation Models, iii) Remote sensing index (VCI) based empirical models. While the first two approaches were used by IMD (in collaboration with state agricultural universities) (Ghosh et al., 2014; Singh et al., 2016), the VCI based model is developed by MNCFC (Dubey et al., 2016).

Remote sensing-based rice yield was estimated using MODIS NDVI (250m resolution) based Vegetation Condition Index (VCI). For the purpose VCI computation, data from 2006 to 2017 during Kharif Rice growing period (June 1st Fortnight to September 1st Fortnight) was used. Step wise regression was carried out between DES yield and VCI. Weather based yield estimation was carried out by IMD using weekly weather (Rainfall, Maximum temperature, Minimum Temperature, Maximum and Minimum Relative Humidity) data of last 10 years, using data upto 1st fortnight of September 2017.

District level yield estimates, derived from the above three approaches, were combined statistically to get the final yield estimate. Different methodologies or yield estimation are given in the table 3 .

\subsection{Accuracy Assessment}

The accuracy of the classified results was evaluated using ground truth data. The ground truth data was available for most of the state included the crops such as kharif rice, cotton, sugarcane and other competitive kharif season crops. In rule based classification, there may be possibility of non-rice pixels getting classified as rice if there is use of complete enumeration approach. Therefore, sample segments have been used instead of complete enumeration to minimize the error or over estimation of crop area. Rule formation and classification was carried out with the support from state remote sensing centre 
officials having adequate information of crop pattern and major changes taken place in their respective states. The classified segments were assessed with overall accuracy and kappa coefficient. $\mathrm{R}^{2}$ and root mean square errors were calculated for acreage, production and yield in comparison with DES data.

\begin{tabular}{|l|l|}
\hline Year & Methodology \\
\hline 2012 & Correlation weighted agro-meteorological model \\
\hline 2013 & $\begin{array}{l}\text { Correlation weighted agro-meteorological model + } \\
\text { yield estimates using SAR data based biomass } \\
\text { modelling }\end{array}$ \\
\hline 2014 & $\begin{array}{l}\text { Correlation weighted agro-meteorological model + } \\
\text { yield estimates using SAR data based biomass } \\
\text { modelling }\end{array}$ \\
\hline 2015 & $\begin{array}{l}\text { Agromet+ crop simulation models+ yield estimated } \\
\text { from RS based CCE }\end{array}$ \\
\hline 2016 & $\begin{array}{l}\text { Correlation weighted agro-met model + VCI remote } \\
\text { sensing-based model }\end{array}$ \\
\hline 2017 & $\begin{array}{l}\text { Correlation weighted agro-meteorological model + } \\
\text { crop simulation models + yield estimates using SAR } \\
\text { data based VCI models }\end{array}$ \\
\hline
\end{tabular}

Table3. Different methodologies for yield estimation

\section{RESULTS AND DISCUSSION}

\subsection{Accuracy Assessment}

Accuracy assessment was carried out in selected parts of the study area to evaluate the classification results. The overall accuracy in the Haryana state was 79.49 with kappa coefficient 0.41. In the Andhra Pradesh state, the overall accuracy was 79.41 with kappa coefficient of 0.51 . It has been found moderate classification agreement on the basis of kappa coefficient with higher overall accuracy. The RMSE per cent ranged from 2.3 to $4.3 ; 0.84$ to $1.35 ; 0.24$ to 0.27 for area, production and yield respectively. The coefficient of determination $\left(\mathrm{R}^{2}\right)$ ranged from 0.62 to $0.92 ; 0.75$ to $0.91 ; 0.5$ to 0.83 for area, production and yield respectively. The $\mathrm{R}^{2}$ year wise graphs are given in annexure I.

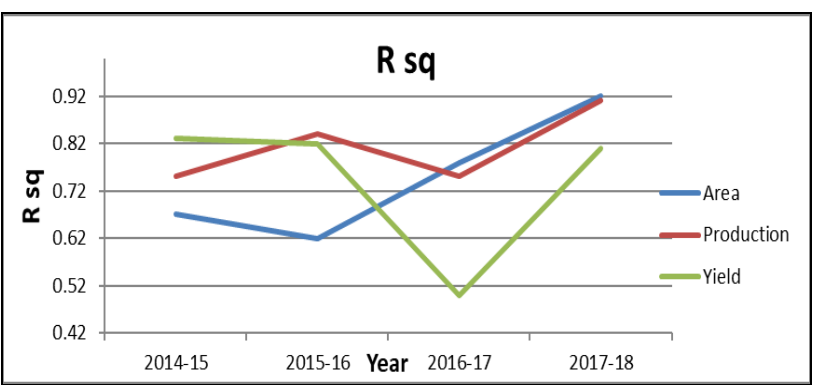

Figure 9. Coefficient of determination for area, yield and production

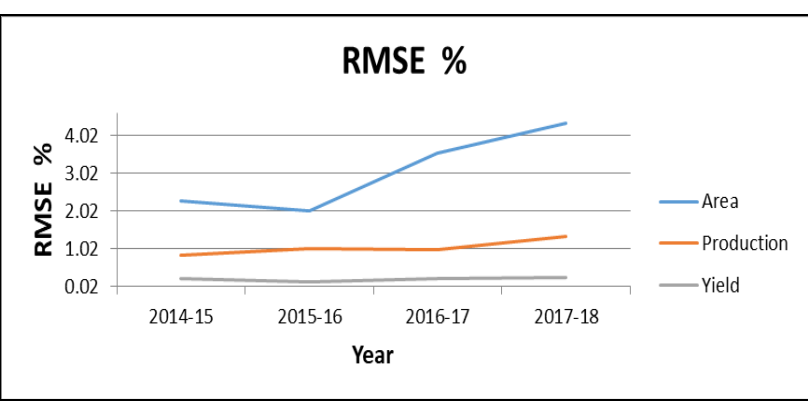

Figure 10: Coefficient of determination for area, yield and production

\subsection{Rice Transplantation Temporal Pattern Based Upon Remote Sensing and Ground Truth Data}

The rules were formed to extract rice pixels at 12- or 24-days interval and those pixels which were classified under particular date range considered as transplantation during that phase. Classified images are shown in figures 11, 12. Transplantation progress is shown in figure 13. It could be inferred from figure 13 that transplantations took place between mid-June to midJuly in the state of Haryana, whereas major transplantations took place between mid-July to mid-August for West Bengal. Similar transplantation graphs were prepared for all paddy growing states of the country.

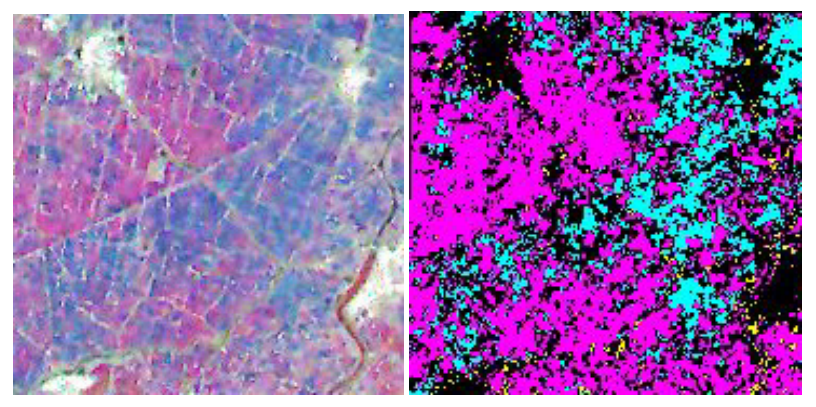

Figure 11: RISAT-1 Multi temporal image (2016) (left) and classified (right) parts of West Godavari district of Andhra Pradesh

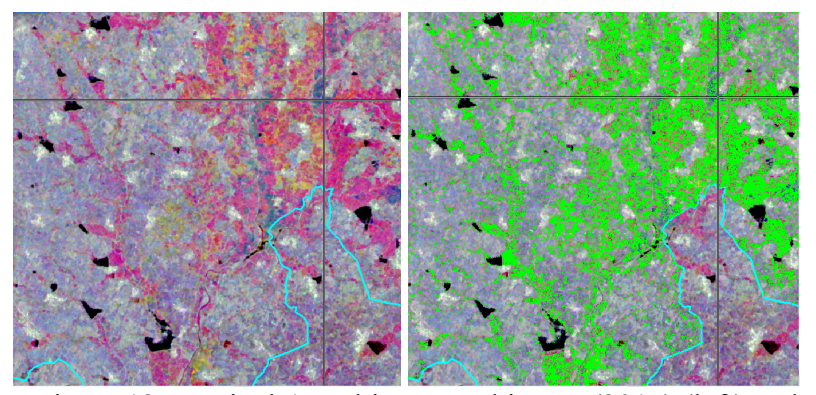

Figure 12: Sentinel-1 Multi temporal image (2017) (left) and classified (right) parts of Khammam district of Telangana 


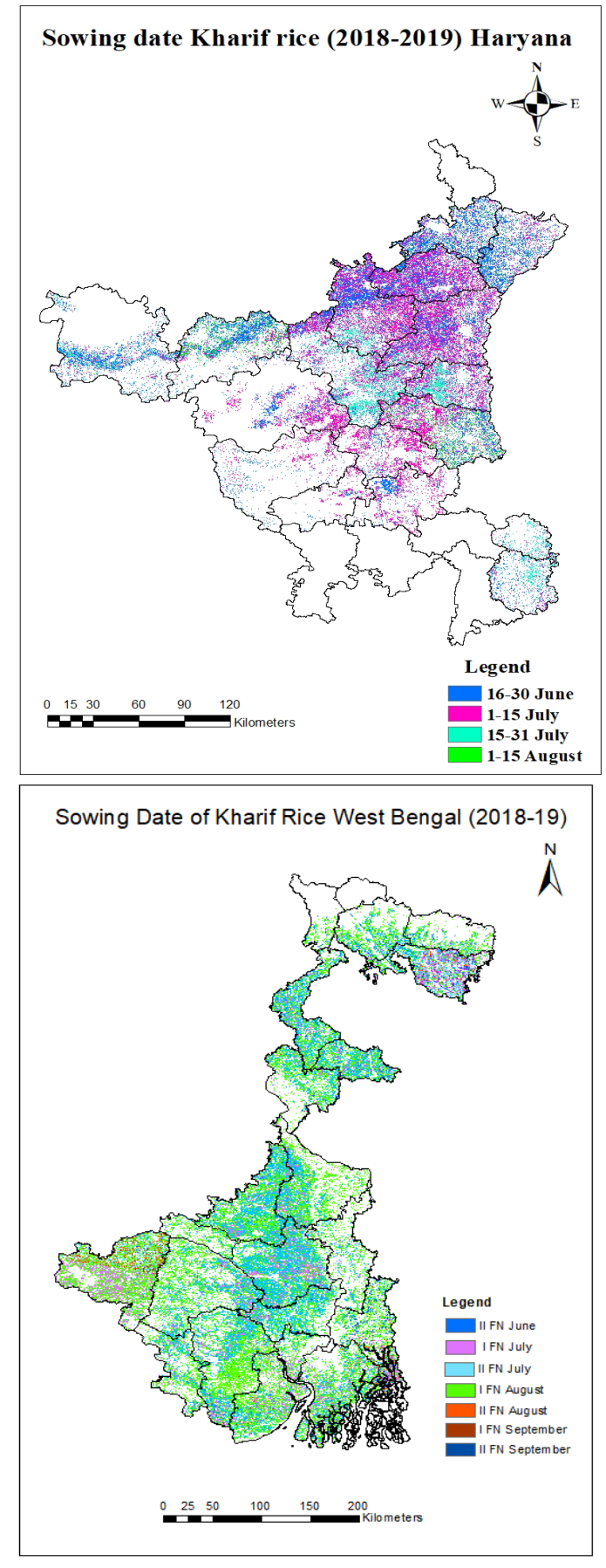

Figure 13: Rice transplantation progress in the states of Haryana (above) and West Bengal (below).

The transplantation information also extracted from ground truth data. Similar pattern has been found between the remote sensing based and ground truth data-based rice transplantation temporal pattern in the country. On the basis of ground truth data, there was $45 \%$ transplantation was completed upto 29 june in the Haryana state and it was $57 \%$ when observed through remote sensing data (Figure 12).

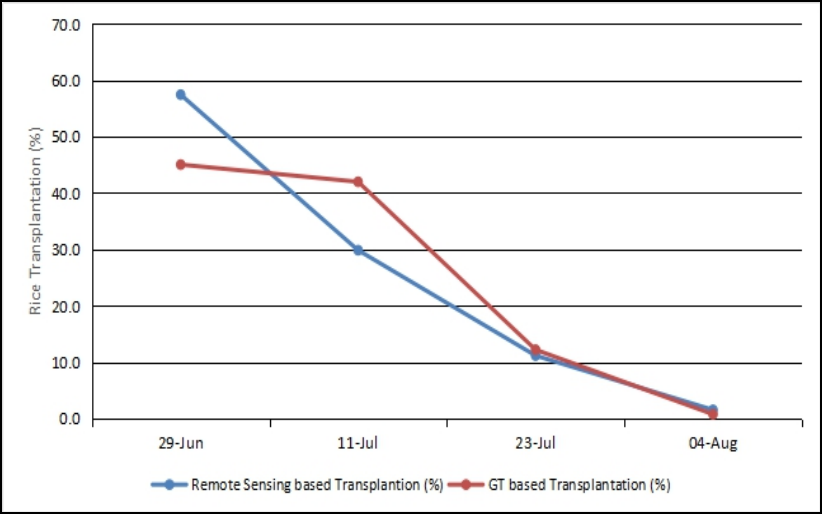

Figure 14: Rice transplantation (\%) temporal pattern identified using SAR data and ground truth data in the Haryana state

As shown in the graph transplantation in Haryana was completed upto first week of august. In case of West Bengal most of the rice (60\%) transplanted in mid-july (Figure13). It is continued upto 3rd week of August.

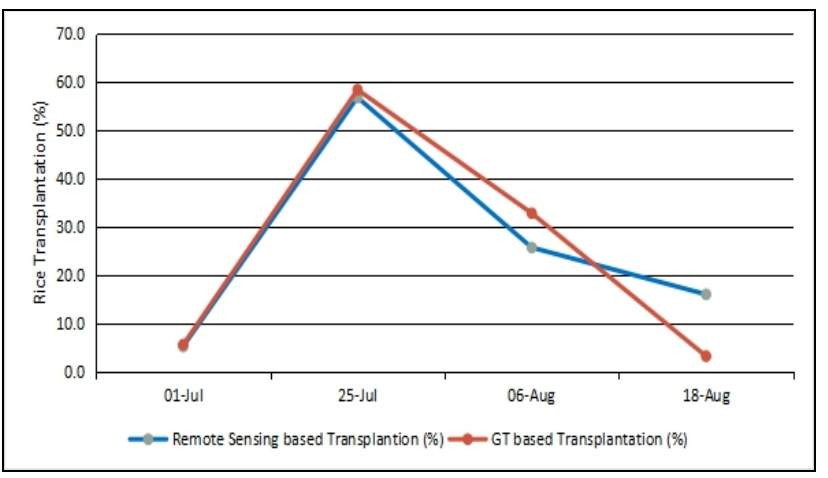

Figure 15: Rice transplantation (\%) temporal pattern identified using SAR data and ground truth data in the West Bengal state

\begin{tabular}{llllllll}
\hline \multicolumn{1}{c}{ State } & \multicolumn{5}{c}{ Acreage } & \multicolumn{4}{c}{ CV } \\
& $2014-15$ & $2015-16$ & $2016-17$ & $2017-18$ & 2014 & 2015 & 2016 \\
\hline AP & 1.3 & 1.34 & 1.34 & 1.49 & 2.29 & 2.37 & 2.36 \\
Assam & 2.1 & 2.08 & 2.09 & 1.95 & & & 1.96 \\
Bihar & 2.52 & 2.97 & 3.01 & 2.21 & & 1.6 & 1.43 \\
Chhattisgarh & 3.34 & 3.54 & 3.67 & 3.51 & 1.61 & 1.31 & 1.28 \\
Haryana & 1.17 & 1.17 & 1.2 & 1.28 & & 2.28 & \\
Jharkhand & 1.37 & 1.39 & 1.38 & 1.39 & & 1.81 & 1.79 \\
Karnataka & 0.94 & 0.89 & 0.86 & 0.7 & 3.34 & 3.08 & 2.37 \\
MP & 1.62 & 1.68 & 1.68 & 1.91 & 3.27 & 2.95 & 2.84 \\
Odisha & 3.4 & 3.71 & 1.91 & 3.53 & & & 1.18 \\
Punjab & 2.74 & 2.72 & 2.76 & 2.68 & & 1.52 & 1.43 \\
Telangana & 0.9 & 0.603 & 0.84 & 0.76 & 2.61 & & 2.52 \\
UP & 5.47 & 5.57 & 5.62 & 5.79 & 1.23 & 1.15 & 1.41 \\
WB & 3.82 & & 3.86 & 3.86 & & & 1.05 \\
\hline
\end{tabular}

Table 3. Acreage (MHa) versus CV values for different years. 


\section{CONCLUSIONS}

Temporal Radarsat-2, RISAT-1 and Sentinel 1A C band data has been analyzed using hierarchical rule-based classification (HDRC) technique within sample segments to generate district level pre-harvest rice acreage estimation in the 14 major kharif rice growing states of the country. SAR C band VV polarization data has shown the great potential to map rice fields in case of non-availability of $\mathrm{HH}$ polarization data. High temporal resolution aided to monitor the rice transplantation temporal pattern in each study area state. The sample segment approach was followed to minimize the errors due to omission and commission in classification. Ground truth data was utilized to assess the accuracy of the classification results and correlated with transplantation temporal pattern extracted using remote sensing data. SAR based pre-harvest rice area monitoring can help in decisions related to food crop management, procurement, and to support food security programmes. In future, continuous availability of Sentinel 1A data in public domain including $\mathrm{HH}$ polarization can support the reliable and timely information related to crop area estimates and can improve the accuracy and results.

\section{ACKNOWLEDGEMENTS}

The crop estimation work has been carried out under the FASAL (Forecasting Agricultural output using Space, Agrometeorology and Land based observations) of Department of Agriculture, Cooperation \& Farmers Welfare (DAC\&FW). The authors are thankful to the senior officials of DAC\&FW, for their strong support and keen interest in the work. The ground truth data collected and expert knowledge provided for remote sensing data analysis by the officials of the State Agriculture Departments and State Remote Sensing Centres, are gratefully acknowledged. The satellite data provided by ISRO (RISAT 1), ESA (Sentinel 1/1A), NASA (MODIS \& Landsat-8), Radarsat 2 and the weather data provided by IMD are thankfully acknowledged. Thanks, are also due to the Analysts of FASAL team, who carried out the annual rice crop analysis. Thanks are also due to scientists of SAC(ISRO), who developed the procedures for crop estimation under FASAL project.

\section{REFERENCES}

Chen, C.F., Son, N.T., Chen, C.R., Chang, L.Y., Chiang, S.H., 2016. Rice crop mapping using sentinel-1A phenological metrics, The International Archives of the Photogrammetry, Remote Sensing and Spatial Information Sciences, Volume XLI-B8, 2016 XXIII ISPRS Congress, 12-19 July 2016, Prague, Czech Republic.

Choudhary, Indrani, Chakraborty, Manab, Santra, S.C., Parihar, J.S., 2012. Methodology to classify rice cultural types based on water regimes using multi-temporal RADARSAT-1 data. Int. Journal of Rem. Sens., vol 33, issue13 pp 4135-4160.

Craig, Michael, and Atkinson, Dale, 2013. A Literature Review of Crop Area Estimation, UN-FAO, Rome, Italy.

Dubey, S. K., Gavli, A. S., Yadav, S. K., Sehgal, Seema \& Ray, S. S. (2018) Remote Sensing-based Yield Forecasting for
Sugarcane (Saccharum officinarum L.). J Indian Soc Remote Sens, 46(11):1823-1833.

Ghosh, K., Balasubramanian, R., Bandopadhyay, S. Chattopadhyay, N., Singh, K.K. and Rathore, L.S., 2014, Development of crop yield forecast models under FASAL- a case study of kharif rice in West Bengal. Journal of Agromet., $16(1), 1-8$.

Henderson, F.M. and Lewis, A.J., 1998. Principles and Applications of Imaging Radar. Manual of Remote Sensing. 3rd Edition. John Wiley and Sons, New York.

Inoue,Y., Kurosu, T., Maeno, H., Uratsuka, S., Kozu, T., Dabrowska-Zielinska, K., Qi, J., 2002. Season Long daily measurements of multifrequency ( $\mathrm{Ka}, \mathrm{K}, \mathrm{X}, \mathrm{C}$ and $\mathrm{L})$ and full polarization backscatter signatures over paddy rice field and their relationship with biological variables. Remote Sensing of Environment, vol 81, issue 2-3, 194-204.

Jain, Varunika, Patnaik, C., Panigrahy, S., 2014. A Feasibility study on Identification of Basmati (aromatic) rice using SAR data. Journal of Earth System Science 123, no 8., 1831-1838.

Lam-Dao, N., Le-Toan, T. \& Floury, N., 2005. The Use of SAR Data for Rice Crop Monitoring- A Case Study of Mekong River Delta - Vietnam. The $26^{\text {th }}$ Asian Conference on Remote Sensing. Ha Noi, Vietnam.

Panigrahy, S., M. Chakraborty, K.R. Manjunath, N. Kundu \& J.S. Parihar, 2000. Evaluation of Radarsat ScanSAR synthetic aperture radar data for rice crop inventory and modeling. Journal of Indian Society of Remote Sensing 28, pp 9-65.

Ray, S. S. \& Neetu. 2017. Crop area estimation with Remote Sensing. In: J. Delincé (ed.), Handbook on Remote Sensing for Agricultural Statistics (Chapter 5). Global Strategy Improving Agricultural and Rural Statistics (GSARS), FAO Statistics Division (ESS), FAO, Rome. pp. 131-183.

Ray, S.S., Neetu, Manjunath, K.R. and Singh, K.K., 2016. Crop Production Forecasting using Space, Agro-meteorology and Land based Observations: Indian Experience. Presented in International seminar on approaches and methodologies for crop monitoring and production forecasting, 25-26 May 2016, Dhaka, Bangladesh.

Singh, P. K., Singh, K. K, Rathore, L. S., Baxla, A. K., Bhan, S. C., Gupta, Akhilesh, Gohain, G.B., Balasubramanian, R., Singh, R. S. and Mall, R. K., 2016. Rice (Oryza sativa L.) yield gap using the CERES-rice model of climate variability for different agroclimatic zones of India. Current Science, 110( 3), 405-413.

Verma, P., 2017. Rice Productivity and Food Security in India. An Overview of Rice Economy, Ch2, Centre for Management in Agriculture (CMA), Indian Institute of Management Ahmedabad (IIMA), DOI 10.1007/978-981-10-3692-7_2

Vogel, A., Bange, Gerald A., 1999. Understanding Crop Statistics. Miscellaneous Publication No. 1554, U.S Department of Agriculture, USA. 


\section{APPENDIX}

District wise Acreage ('000 ha) Comparison of Kharif Paddy DES and FASAL Estimates 2014-15

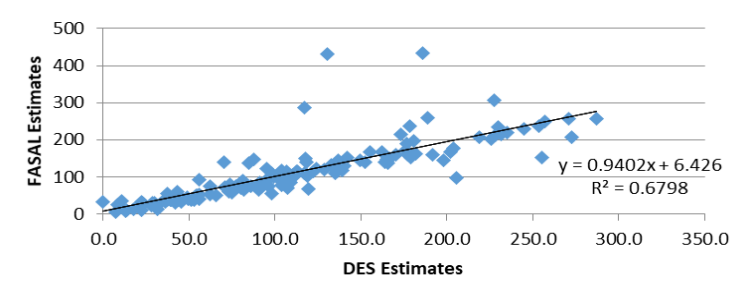

District wise Yield (kg/ha) Comparison of Kharif Paddy DES and FASAL Estimates 2014-15

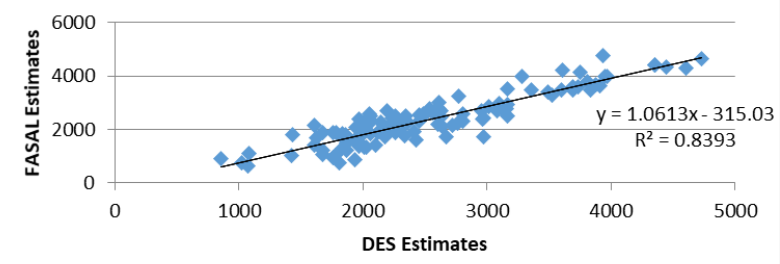

District wise Production ('000 tonnes)

Comparison of Kharif Paddy DES and FASAL Estimates 2014-15



District wise Acreage ('000 ha) Comparison of Kharif Paddy DES and FASAL Estimates 2015-16

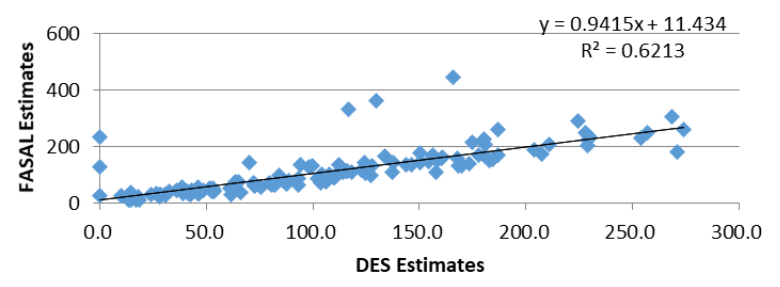

District wise Yield (kg/ha) Comparison of Kharif Paddy DES and FASAL Estimates 2015-16

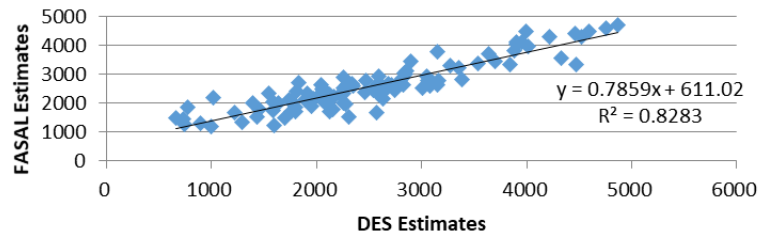

District wise Production('000 tonnes) Comparison of Kharif Paddy DES and FASAL Estimates 2015-16

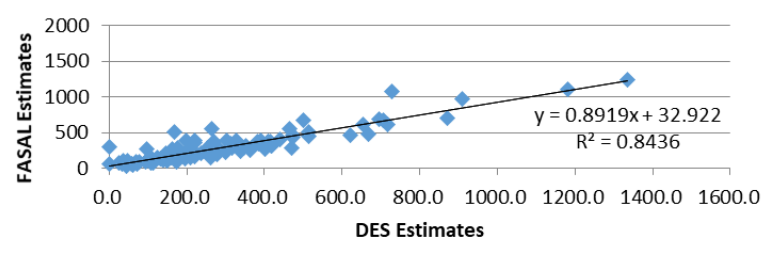

District wise Acreage ('000 ha) Comparison of Kharif Paddy DES and FASAL Estimates 2016-17

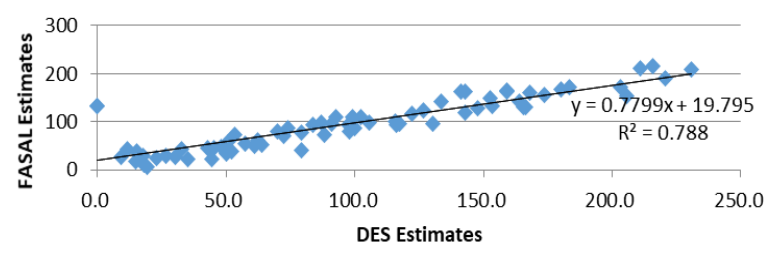

District wise Yield (kg/ha) Comparison of Kharif Paddy DES and FASAL Estimates 2016-17

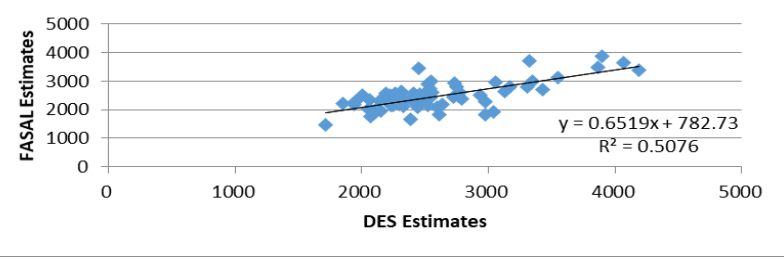

District wise Production ('000 tonnes) Comparison of Kharif Paddy DES and FASAL Estimates 2016-17

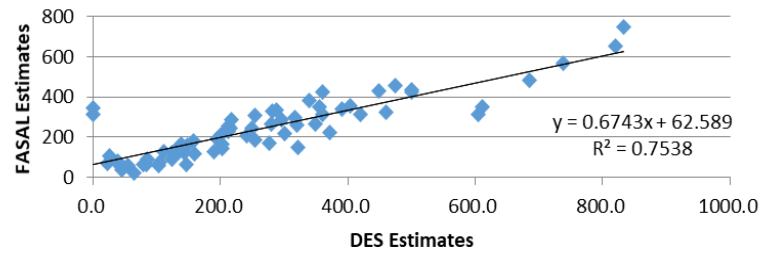

